\title{
ANALISIS PENAMBAHAN PIPA DISTRIBUSI AIR BERSIH PADA JEMBATAN DIATAS SUNGAI BATEE ILIEK SAMALANGA BIREUEN
}

\author{
(Analysis of Addition of Clean Water Distibution Pipes on The lliek Samalanga Bireun \\ Batee River)
}

Mohammad Imamuddin ${ }^{1}$, Mukhibullah ${ }^{1}$

'Jurusan Teknik Sipil Universitas Muhammadiyah Jakarta.

E-mail: imamuddin0002@gmail.com,

\begin{abstract}
ABSTRAK
Pada Tahun 2018 dalam rangka cakupan pelayanan air bersih PDAM Krueng Peusangan Kabupaten Bireuen di wilayah cabang IKK Kecamatan Samalanga sampai saat ini belum optimal dari total penduduk Kecamatan Samalanga 31.203 jiwa / 6442 KK. Selain dari cakupan pelayanan yang belum optimal terdapat permasalahan lain yaitu pipa existing yang melintas pada jembatan sungai Bate llieik panjang $37.5 \mathrm{~m}$ terjadi korosi sampai terjadinya kebocoran. Dalam memenuhi kebutuhan air bersih meninjau pada perlintasan sungai dengan memperhitungkan analisis kehilangan air (head loss), dimensi pipa, kebutuhan debit, sisa tekanan aliran di ujung pipa dalam pipa dan juga struktur penambahan pipa. Dari hasil analisis penelitian ini diantaranya dimensi pipa yang dibutuhkan adalah : diameter $200 \mathrm{~mm}$, debit aliran pada $4500 \mathrm{KK}$ adalah : $35.94 \mathrm{ltr} /$ detik, Total head loss energy sekunder pada jaringan pipa adalah : $44.04 \mathrm{~m}$ sedangkan kehilangan energi air (head loss energy) sekunder losses dan minor losses dijembatan adalah : 0.48 meter atau $1.09 \%$ dan juga sisa tekanan diujung diperoleh 1.48 bar masih memenuhi persyaratan minimum pipa distribusi SNI 7509:2011 adalah 1 bar sehingga system secara teknis mampu mendistribusikan air secara gravitasi, untuk penambahan pipa pada jembatan sungai analisa struktur mampu untuk penambahan pipa.
\end{abstract}

Kata Kunci : Penambahan pipa air bersih, Jembatan pipa, Pipa PDAM

\begin{abstract}
In 2018 in the framework of the coverage of clean water services in the Krueng Peusangan PDAM, Bireuen Regency in the IKK branch area, Samalanga District, to date has not been optimal from the total population of Samalanga District, 31,203 inhabitants / 6442 households. Apart from the suboptimal service coverage, there are other problems, namely the existing pipeline that crosses the Bate llieik river bridge, which is 37.5 $m$ long, corrosion occurs until leakage occurs. In meeting the need for clean water, take a look at river crossings by calculating head loss analysis, pipe dimensions, discharge requirements, residual flow pressure at the end of the pipe in the pipe and also the structure of the pipe addition. From the results of the analysis of this study include the dimensions of the pipes needed are: diameter $200 \mathrm{~mm}$, flowrate at $4500 \mathrm{KK}$ is: $35.94 \mathrm{ltr} / \mathrm{sec}$, the total secondary head loss energy in the pipeline is: $44.04 \mathrm{~m}$ while secondary water loss (head loss energy) losses and minor losses on the bridge are: 0.48 meters or $1.09 \%$ and also the remaining pressure at the end obtained 1.48 bar still meets the minimum requirements of SNI 7509: 2011 distribution pipe is 1 bar so the system is technically able to distribute water gravity, for the addition of pipes on the river bridge analysis structure capable of adding pipes
\end{abstract}

Keywords: additional, clean water pipe bridge, pipe the company 


\section{PENDAHULUAN}

Perusahaan Daerah Air Minum (PDAM) Krueng Peusangan Kabupaten Bireuen akan melakukan peningkatan pengembangan pelayanan air bersih kepada masyarakat dengan pelanggan yang sudah terdaftar kepada pihak PDAM sebanyak 4500 KK dari dua Kecamatan dengan jalur pipa rencana 10875 meter.

Pada saat tinjauan pelayanan air bersih, ditemukan beberapa masalah yang terjadi pada jalur pipa existing dengan panjang total 4235 meter, yaitu cakupan pelayanan yang masih belum maksimal, terjadi kekurangan debit air pada jaringan distribusi air didaerah hillir. Hal ini diakibatkan karena system pendistribusian pada daerah hulu tidak menggunakan sistem looping pada pipa distribusi layanan kepipa distribusi utama, sehingga pada daerah hilir tidak mendapatkan air bersih dan juga terjadinya kebocoran akibat korosinya pada air valve dan flange pada elbow disetiap perlintasan sungai sehingga air terbuang siasia. Terjadi korosi pada pipa perlintasan Sungai Batee lliek panjang 37.5 meter, dari permasalahan diatas maka perlu pengembangan pipa diatas sungai, guna untuk mengotimalkan pendistribusian air bersih kepada masyarakat.

Tujuan penelitian ini adalah :

a. Untuk mengatahui berapakah diameter pipa dan debit pada jumlah pelanggan $4500 \mathrm{KK}$.

b. Untuk mengetahui kehilangan energi (headloss) air dari jenis pipa sepanjang perlintasan sungai.

c. Untuk mengetahui tekanan air minimum sesuai $\mathrm{SNI}$ 7509:2011?

d. Untuk mengetahui struktur penambahan pipa.

\section{TINJAUAN PUSTAKA}

a. Analisis Debit Rencana

Menurut Soemarto (1987) debit diartikan sebagai volume air yang mengalir persatuan waktu melewati suatu penampang melintang palung sungai, pipa, pelimpah dan sebagainya maka satuan debit adalah satuan volume per satuan waktu.

Persamaan mencari debit menggunakan persamaan Hazen Williams :

$\mathrm{Q}=0.27853 \times C \times D^{2.63} \times S^{0.54}$

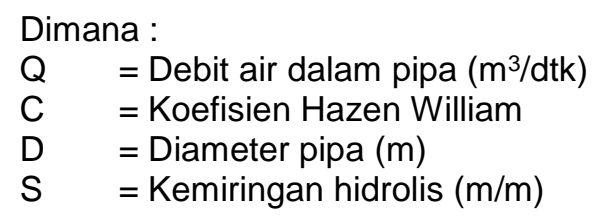

b. Analisis Dimensi Pipa

$$
\left\{\frac{3.59 \times 10^{6} \times \text { Qtotal }}{6 \times S^{1 .: 54}}\right\}^{0.38}
$$

Dimana :

$\mathrm{Q}=$ Debit air dalam pipa $\left(\mathrm{m}^{3} / \mathrm{dtk}\right)$

$\mathrm{C}=$ Koefisien Hazen William

$\mathrm{S}=$ Kemiringanhidrolis $(\mathrm{m} / \mathrm{m})$

c. Analisis Kehilangan Energi

Menurut Denik Srikinayati (2013) Kehilangan tinggi total (head losses) adalah head atau kerugiankerugian dalam aliran pipa yang terdiri atas mayor losses dan minor losses

Sumber : (Klass.K.S.Y, $2009: 15)$

$$
h L=h f+h m
$$

Di mana :

$\mathrm{hL}=$ kehilangan tinggi total $(\mathrm{m})$

$\mathrm{hf}=$ kehilangan energy akibat factor gesekan pipa (m)

$\mathrm{hm}=$ kehilangan energy akibat factor perubahan penampang pipa,

belokan dan perubahan arah aliran pada pipa $(\mathrm{m})$.

\section{Persamaan Hazen Williams}

Persamaan Hazen Williams sebagai berikut :

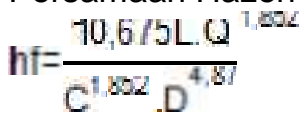

Dimana :

$\mathrm{hf}=$ Kehilangan energy oleh tahanan permukaan pipa $(\mathrm{m})$

$\mathrm{L}=$ Panjang Pipa $(\mathrm{m})$

$\mathrm{Q}=$ Debit aliran ( $\left.\mathrm{m}^{3} / \mathrm{dtk}\right)$

$\mathrm{C}=$ Koefisien Hazem William

$\mathrm{D}=$ Diameter pipa

$h_{m}=n_{1} K \frac{v^{2}}{2 \cdot y}$

\section{Dimana :}

$\mathrm{h}_{\mathrm{m}}=$ kehilangan energi minor $(\mathrm{m})$

$\mathrm{n}=$ Jumlah pipe fitting (bh)

$\mathrm{K}=$ Koefisien kehilangan tekanan

minor (pada tabel)

$\mathrm{V}=$ Kecepatanaliran (m/dtk)

$G=$ Percepatan gravitasi $\left(m / d t k^{2}\right)$

\section{d. Analisis Tekanan Air}

Pada Standar Nasional Indonesia (SNI 7509:2011) terdapat besaran tekanan air minimum di dalam pipa

\begin{tabular}{|c|c|}
\hline $\begin{array}{l}\text { Jenis Jaringan } \\
\text { Jarngan Distribusi Utama } \\
\text { Jaringan IVistrihusi Pambagi } \\
\text { Sambrungan Petarggan }\end{array}$ & $\begin{array}{l}\text { Nilui Mininum } \\
\begin{array}{l}15 \mathrm{mair} \\
11 \mathrm{~m} \text { air } \\
7.5 \mathrm{mar}\end{array}\end{array}$ \\
\hline \multicolumn{2}{|l|}{$P^{\prime}=P-(h f+h m)$} \\
\hline \multicolumn{2}{|l|}{ Dimana : } \\
\hline \multicolumn{2}{|c|}{$\mathrm{P}^{\prime}=$ SisaTekanan $(\mathrm{m})$} \\
\hline \multicolumn{2}{|c|}{$\mathrm{P}=$ Tekanan Ujung Pipa (m) } \\
\hline
\end{tabular}
distribusi terdapat table berikut :

Tabel 1. Tekanan air minimum 
$\mathrm{hm}=$ Kehilangan energy sekunder / Minor losses (m)

e. Jenis Kecepatan Aliran

Menurut Waspodo (2015) jenis kecepatan aliran berdasarkan gaya yang terjadi pada fluida dibedakan sesuai table 2 di bawah ini :

Tabel 2. Kecepatan Aliran

\begin{tabular}{|l|c}
\multicolumn{1}{|c|}{ Jenis alirau } & Nilai Ke \\
\hline T.aminer & $<100$ \\
Transisi & $2100<\mathrm{R}<400$ \\
\hline Turhmicn & $>4000$ \\
\hline
\end{tabular}

Rumus persamaan kecepatan aliran $v=0,849 \cdot C \cdot R 0,63 \cdot S 0,54$

Dimana :

$v=$ kecepatan aliran, dalam (m/detik)

$C=$ koefisien Hazen William

$R=$ jari-jari pipa, dalam (m)

$S=$ slope/kemiringan hidrolis $(\mathrm{m} / \mathrm{m})$

f. Analisis struktur lendutan dan tegangan jembatan pipa

\section{Lendutan}

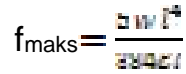

Dimana :

$$
\begin{array}{ll}
\mathrm{F} & =\text { Lendutan }(\mathrm{m}) \\
\mathrm{W} & =\text { Gaya }(\mathrm{Kg}) \\
\mathrm{L} & =\text { Panjang }(\mathrm{m}) \\
\mathrm{E} & =\text { Modulus Elastisitas }\left(\mathrm{N} / \mathrm{m}^{2}\right) \\
\mathrm{I} & =\text { Momen Inersia }\left(\mathrm{mm}^{4}\right)
\end{array}
$$

\section{Tegangan}

$$
u_{\text {maks }}=\frac{M}{W X}
$$

Dimana :

$$
\mathrm{M} \quad=\text { Momen Primer }(\mathrm{kg} / \mathrm{cm})
$$$$
\mathrm{Wx}=\text { Momen Lawan }\left(\mathrm{cm}^{3}\right)
$$

\section{METODOLOGI PENELITIAN}

Penelitian ini dilakukan pada jembatan pipa sungai Batee Iliek Samalanga pada bulan Juli 2018

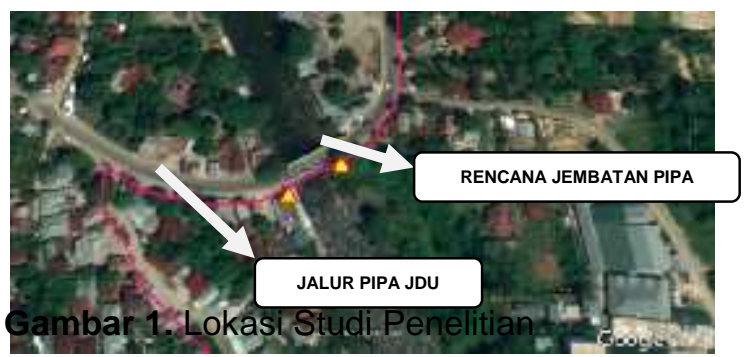

\section{Pengumpulan Data}

Adapun data yang diperlukan untuk penelitian ini antara lain data primer dan data sekunder.

1. Data Primer

Yaitu data yang diperoleh hasil pengukuran dilapangan terkait rencana pengembangan pipa JDU (Jaringan Distribusi Utama) diantaranya :

$>$ Panjang rencana pipa = 10875 meter

$>$ Panjang jembatan pipa $\quad=\quad 37.5$ meter

$>$ Elevasi di Reservoir $\quad\left(\mathrm{h}^{1}\right)=\quad+89.1$ meter

$>$ Elevasi di titik jembatan $\left(\mathrm{h}^{2}\right) \quad=\quad+44$ meter

$>$ Elevasi di ujungpipa $\quad\left(\mathrm{h}^{3}\right)=+15.57$ meter

2. Data Sekunder

Yaitu Data yang diperoleh peneliti dari sumber asli yaitu pihak instansi terkait PDAM.

$>$ Jumlah KK yang terdaftar $3000 \mathrm{KK}$

> Jumlah KK Existing 1500 KK

\section{AnalisisData}

a. Analisis Debit Rencana

Menurut Soemarto (1987) debit diartikan sebagai volume air yang mengalir persatuan waktu melewati suatu penampang melintang palung sungai, pipa, pelimpah dan sebagainya maka satuan debit adalah satuan volume per satuan waktu. Persamaan mencari debit menggunakan persamaan Hazen Williams :

$$
Q=0.27853 \times C \times D^{2.63} \times S^{0.54}
$$

Dimana :

$\mathrm{Q}=$ Debit air dalampipa ( $\left.\mathrm{m}^{3} / \mathrm{dtk}\right)$

$\mathrm{C}=$ Koefisien Hazen William

$\mathrm{D}=$ Diameter pipa $(\mathrm{m})$

$\mathrm{S}=$ Kemiringanhidrolis $(\mathrm{m} / \mathrm{m})$

b. Analisis Dimensi Pipa

$$
\left\{\frac{3.59 \times 10^{6} \times \text { Qtotal }}{6 \times 5^{0 .: 14}}\right\}^{0.38}
$$

Dimana :

$\mathrm{Q}=$ Debit air dalampipa ( $\left.\mathrm{m}^{3} / \mathrm{dtk}\right)$

$\mathrm{C}=$ Koefisien Hazen William

$\mathrm{S}=$ Kemiringanhidrolis $(\mathrm{m} / \mathrm{m})$

c. Analisis Kehilangan Energi

$$
\mathbf{h L}=\mathbf{h f}+\mathbf{h m}
$$

Di mana :

$\mathrm{hL}=$ kehilangan tinggi total $(\mathrm{m})$

$\mathrm{hf}=$ kehilangan energy akibat factor gesekan pipa (m)

$\mathrm{hm}=$ kehilangan energy akibat factor perubahan penampang pipa,

belokan dan perubahan arah aliran pada pipa (m). 


\section{Persamaan Hazen Williams}

Persamaan Hazen Williams sebagai berikut :

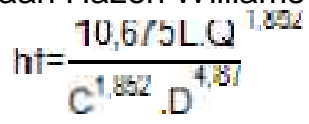

Dimana :

$\mathrm{hf}=$ Kehilangan energy oleh tahanan permukaan pipa $(\mathrm{m})$

$\mathrm{L}=$ Panjang Pipa $(\mathrm{m})$

$\mathrm{Q}=$ Debit aliran ( $\left.\mathrm{m}^{3} / \mathrm{dtk}\right)$

$\mathrm{C}=$ Koefisien Hazem William

$\mathrm{D}=$ Diameter pipa

$$
\mathrm{h}_{\mathrm{m}}=n \cdot \mathrm{K} \frac{\underline{v}^{2}}{2, \mathrm{~g}}
$$

Dimana :

$\mathrm{h}_{\mathrm{m}}=$ kehilangan energi minor $(\mathrm{m})$

$\mathrm{n}=$ Jumlah pipe fitting (bh)

$\mathrm{K}=$ Koefisien kehilangan tekanan

minor (padatabel)

$\mathrm{V}=$ Kecepatan aliran $(\mathrm{m} / \mathrm{dtk})$

$g=$ Percepatan gravitasi $\left(m / d t k^{2}\right)$

d. AnalisisTekanan $\mathrm{Ai}$

$P^{\prime}=P-(h f+h m)$

Dimana :

$\mathrm{P}^{\prime}=$ Sisa Tekanan $(\mathrm{m})$

$\mathrm{P}=$ Tekanan Ujung Pipa $(\mathrm{m})$

$\mathrm{hf}=$ Kehilangan energi Primer / Mayor losses $(\mathrm{m})$

$\mathrm{hm}=$ Kehilangan energy sekunder / Minor losses (m)

e. Analisis struktur lendutan dan tegangan jembatan pipa

Lendutan

$$
f_{\text {maks }}=\frac{3 w l^{*}}{a v 4 \varepsilon i}
$$

Dimana :

$\mathrm{F}=$ Lendutan $(\mathrm{m})$

$\mathrm{W}=$ Gaya $(\mathrm{Kg})$

$\mathrm{L}=$ Panjang $(\mathrm{m})$

$\mathrm{E}=$ Modulus Elastisitas $\left(\mathrm{N} / \mathrm{m}^{2}\right)$

$\mathrm{I}=$ Momen Inersia $\left(\mathrm{mm}^{4}\right)$

Tegangan

$$
U_{\operatorname{maks}}=\frac{\mathrm{M}}{\mathrm{WX}}
$$

Dimana :

$M=$ Momen Primer $(\mathrm{kg} / \mathrm{cm})$

$\mathrm{W} x=$ Momen Lawan $\left(\mathrm{cm}^{3}\right)$

\section{Flowchart MetodologiPenelitian}

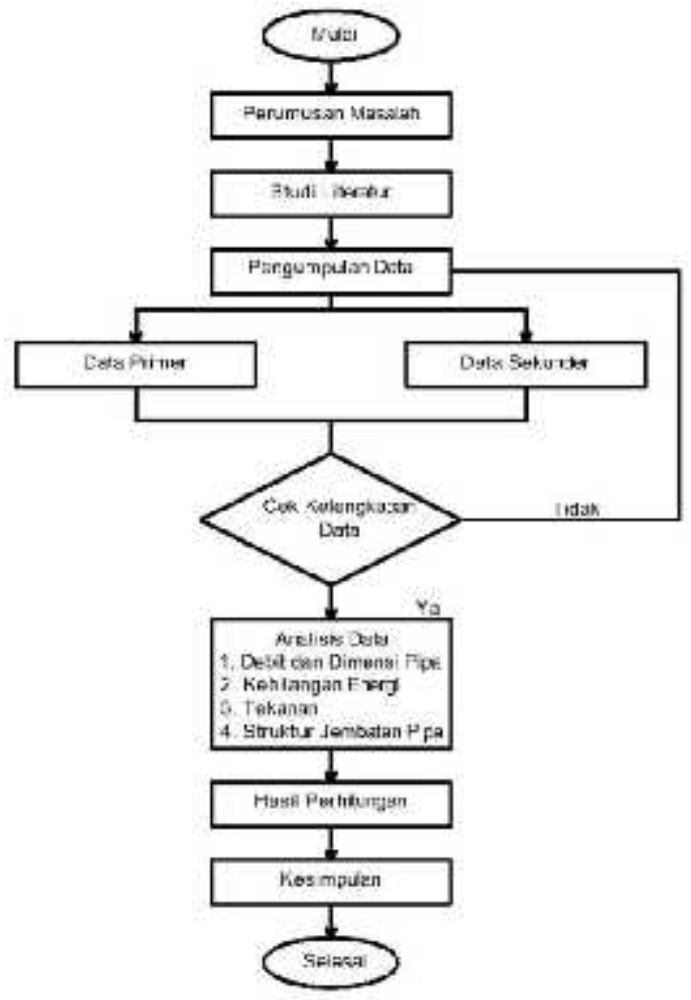

Gambar 1. Flowchart Metodologi Penelitian

\section{HASIL DAN PEMBAHASAN}

a. Analisis Debit Rencana

Tabel 3. Kebutuhan Debit Existing dan Rencana

\begin{tabular}{|c|c|c|c|}
\hline No & Jenis Debit & Jumlah Debit & Satuan \\
\hline 1 & Existing $1500 \mathrm{KK}$ & 11,98 & Ltr/dtk \\
\hline 2 & Rencana $4500 \mathrm{KK}$ & 35,94 & Ltr/dtk \\
\hline
\end{tabular}

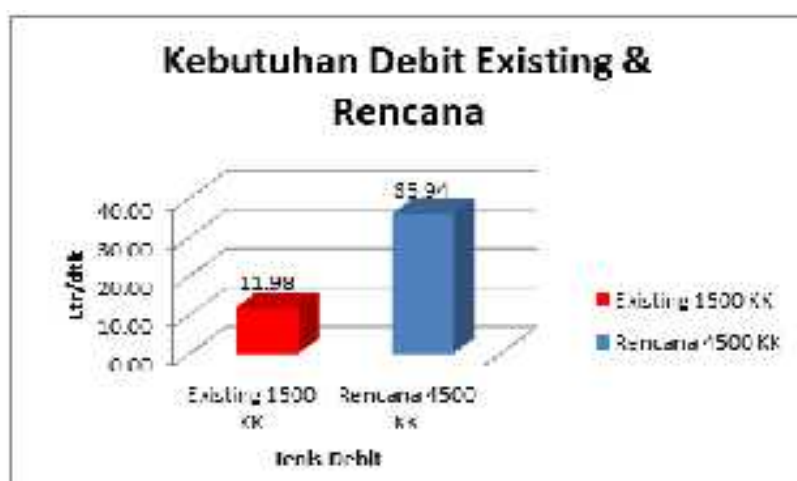

Gambar 2. Kebutuhan Debit Existing dan Rencana 
b. Analisis Dimensi Pipa

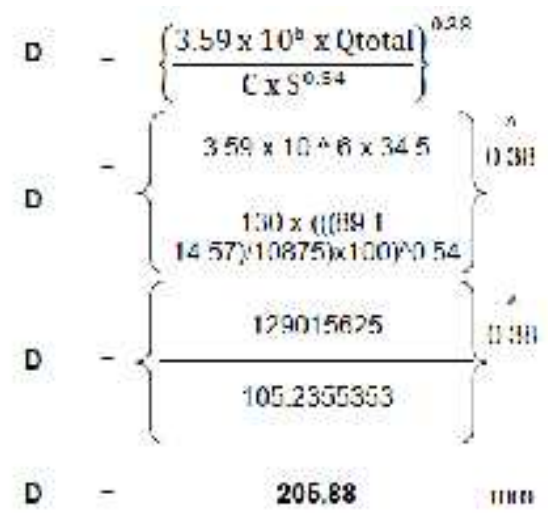

c. Analisis Kehilangan Energi

Tabel 4. Hasil Data Kehilangan Energi

\begin{tabular}{|c|c|c|c|c|c|}
\hline$N_{0}$ & Head Lois & $\begin{array}{l}\text { IIend } \\
\text { I.uss,hr } \\
\text { (Iij) }\end{array}$ & $\begin{array}{l}\text { IIend } \\
\text { tuschium } \\
\text { (m) }\end{array}$ & $\begin{array}{c}\text { Tincil } \\
\text { Head } \\
\text { tans, lit. } \\
\text { [m] }\end{array}$ & $\begin{array}{l}\text { Iread Loss } \\
\text { briil, h1. } \\
\text { (m) }\end{array}$ \\
\hline & Jatur Piya & 42,611 & 2.435 & 44.046 & \multirow{2}{*}{ atis } \\
\hline 2 & $\begin{array}{l}\text { Perlintasen } \\
\text { Sillt"lekan }\end{array}$ & 0.355 & 0.128 & 0,483 & \\
\hline
\end{tabular}

$\mathrm{P}=$ Tekanan Ujung Pipa - hf\&hm

$\mathrm{P}=15.576-0.483$

$\mathrm{P}=15.093$ meter air $\sim 1.480$ Bar

Syarat Sisa Tekanan Ujung Pipa

$$
\begin{aligned}
& =P \geq \text { PIZIN } \\
& =1.480 \geq 1 \text { Bar AMAN !!! }
\end{aligned}
$$

e. Analisis struktur lendutan dan tegangan jembatan pipa Lendutan

Tabel 5. Hasil lendutan penambahan pipa

\begin{tabular}{|llc|c|}
\hline No & Innls Rehan & $\begin{array}{c}\text { I endutan } \\
\text { Terjedi }(\mathbf{m m})\end{array}$ & $\begin{array}{c}\text { I mentustan } 1 \text { >lin } \\
\text { L/240 (mm) }\end{array}$ \\
\hline 1 & H Jup & 26.00 & 456.25 \\
\hline 2 & Mati & 09.05 & 756.25 \\
\hline 3 & Kontinasi & 129.50 & 756.25 \\
\hline
\end{tabular}

Tegangan

TeganganMaksimal yang terjadi

$$
\begin{aligned}
& \text { бmaks }=\frac{\mathrm{M}}{\mathrm{Wx}} \\
& \sigma \mathrm{maks}=\frac{17064855,5}{18027.6} \\
& \sigma \text { maks }=946.596 \quad \mathrm{Kg} / \mathrm{cm}^{2}
\end{aligned}
$$

Syarat Tengangan

$$
\begin{aligned}
& ={ }^{2} \text { maks } \leq \text { aizin } \\
& =946.596 \leq 1400 \mathrm{Kg} / \mathrm{cm}^{2}
\end{aligned}
$$

AMAN

\section{KESIMPULAN}

1. Debit yang dibutuhkan $35.94 \mathrm{Ltr} / \mathrm{dtk}$ berdasarkan jumlah data KK 4500.

2. Hasil analisis tekanan air ujung pipa diperoleh 15.576 meter air masih menuhi tekanan minimum di jalur pipa distribusi SNI 7509:2011 yaitu 15 meter air, pada hasil sisa tekanan diujung diperoleh 1.480 bar masih memenuhi tekanan di jangkauan terjauh yaitu $0.5-1$ bar. Sehingga dapat disimpulkan air masih bisa mengalir sampai keujung.

3. Penambahan pipa pada jembatan sungai, analisa struktur mampu untuk penambahan pipa diameter $200 \mathrm{~mm}$.

\section{REFERENSI}

Denik Srikinayati. (2013). Studi Perencanaan Pengembangan Penyediaan Air Bersih Di Kecamatan Kupang Timur Kabupaten Kupang.

Waspodo. (2015). Analisa Headloss Sistem Jaringan Pipa Pada Sambungan Pipa Kombinasi Diameter Berbeda.

Peraturan Menteri Pekerjaan Umum dan Perumahan Rakyat No.27. (2016). Penyelenggaraan Sistem Penyediaan Air Minum.

SNI 03-2850-1992. (1992). Tata Cara Pemasangan Utilitas Dijalan.

SNI-7509-2011. (2011). Tata Cara Perencanaan Teknik Jaringan Distribusi dan Unit Pelayanan Sistem Penyediaan Air Minum. 